\title{
Rhizobium tropici response to acidity involves activation of glutathione synthesis
}

\author{
Correspondence \\ O. Mario Aguilar \\ aguilar@biol.unlp.edu.ar
}

Received 16 October 2006

Revised 20 December 2006

Accepted 22 December 2006

\author{
Cecilia I. Muglia, Daniel H. Grasso and O. Mario Aguilar \\ Instituto de Bioquímica y Biología Molecular, Facultad de Ciencias Exactas, Universidad \\ Nacional de La Plata, 1900, La Plata, Argentina
}

\begin{abstract}
Rhizobium tropici CIAT899 displays intrinsic tolerance to acidity, and efficiently nodulates Phaseolus vulgaris at low $\mathrm{pH}$. By characterizing a gsh $B$ mutant strain, glutathione has been previously demonstrated to be essential for $R$. tropici tolerance to acid stress. The wild-type gsh $B$ gene region has been cloned and its transcription profile has been characterized by using quantitative real-time PCR and transcriptional gene fusions. Activation of the gsh $B$ gene under acid-stress conditions was demonstrated. gshB is also induced by UV irradiation. Upstream from gshB a putative $\sigma^{70}$ promoter element and an inverted repeat sequence were identified, which are proposed to be involved in expression under neutral and acidic conditions, respectively. Gel retardation assays indicate that transcription in acid conditions may involve protein binding to an upstream regulatory region.
\end{abstract}

\section{INTRODUCTION}

Rhizobia are soil bacteria able to induce the formation of nitrogen-fixing nodules in symbiosis with different leguminous plants. As such, they are constantly challenged by a variety of stresses, including nutrient limitation and exposure to physical stresses, e.g. elevated temperature, high osmolarity, acidity, or oxidative shock. The capacity of Rhizobium spp. to adapt to these adverse conditions is fundamental for the establishment of an efficient symbiosis. More than one-quarter of the world's cultivable soils are acidic, which makes the study of the mechanisms implied in the survival to acid stress of great agricultural relevance (Tiwari et al., 1996a).

During the different steps of infection, leading to the formation of nitrogen-fixing nodules, the bacteria have to face different stressors. In the first steps of the recognition between the symbiotic partners, the plant produces a defence response against invasion, generating a low level of reactive oxygen species (ROS), such as $\mathrm{O}_{2}^{-}$, which the bacteria have to overcome (Santos et al., 2000). Once the bacterium has differentiated into a nitrogen-fixing bacteroid, a low level of ROS becomes a requirement for the functioning of the nitrogenase enzymes, which are highly oxygen sensitive. At the same time, ROS are continuously being generated by the high rate of respiration that is taking place (Escudero et al., 1996). Different mechanisms of

Abbreviations: qRT-PCR, quantitative real-time reverse transcriptase PCR; ROS, reactive oxygen species.

The GenBank/EMBL/DDBJ accession number for the sequence reported in this paper is DO912168. protection against these ROS have been described, which include catalases, superoxide dismutases, peroxidases and enzymes such as peroxiredoxin (Sigaud et al., 1999; Santos et al., 2000; Jamet et al., 2003; Dombrecht et al., 2005). Small molecules, such as ascorbate and glutathione ( $\gamma$-glutamylcysteinylglycine), also participate in the protection of nodules against oxidative stress (Moran et al., 2000; Iturbe-Ormaetxe et al., 2001; Matamoros et al., 2003). In Sinorhizobium meliloti, glutathione has recently been shown to play a fundamental role in growth and symbiotic efficiency (Harrison et al., 2005). Acidity also becomes a challenge in nodule development, affecting both the bacteria and the plant, as well as their interaction. The level of ROS increases during nodule senescence (Matamoros et al., 1999).

On the other hand, the tripeptide glutathione plays key roles in the physiology of bacterial cells. Indeed, glutathione ensures correct folding, synthesis, regulation and degradation of proteins, affords protection against oxidative stress, and participates in the detoxification of numerous xenobiotics, such as the electrophile methylglyoxal. It is the major low-molecular-mass thiol found in most organisms, where levels can reach concentrations exceeding $10 \mathrm{mM}$ (Penninckx \& Elskens, 1993; Sherrill \& Fahey, 1998; Carmel-Harel \& Storz, 2000; Noctor et al., 2002; Allocati et al., 2003; Lillig et al., 2003; Neumann et al., 2003).

We had previously reported the isolation and characterization of a Rhizobium tropici CIAT899 mutant in the gshB gene (strain CIAT899-13T2), encoding the enzyme glutathione synthetase, which catalyses the second step of the metabolic synthesis of glutathione (Riccillo et al., 2000). Growth of the 
mutant strain CIAT899-13T2 is sensitive to external and intracellular acidification. It is also sensitive to salt stress, oxidative stress and the electrophile methylglyoxal.

This work presents further analysis of the R. tropici gshB gene. The molecular characterization of the $g \operatorname{sh} B$ and its $5^{\prime}$-upstream sequence is presented, and the responsiveness of the gene to acidity and other environmental stresses is shown. The studies described indicate that $g s h B$ is activated under acid-stress conditions and that the promoter sequence forms stable complexes with proteins.

\section{METHODS}

Bacterial strains, plasmids and growth media. Strains and plasmids used are described in Table 1. $R$. tropici strains were grown at $28^{\circ} \mathrm{C}$ in TY medium (Beringer, 1974) or minimal GTS medium (Kiss et al., 1979). For acid-stress experiments, GMS minimal medium was used (pH 5.0 or 4.8 as stated) (Riccillo et al., 2000). Antibiotics were added when needed: $400 \mu \mathrm{g}$ streptomycin $\mathrm{ml}^{-1}$, $100 \mu \mathrm{g}$ neomycin $\mathrm{ml}^{-1}, 5 \mu \mathrm{g}$ tetracycline $\mathrm{ml}^{-1}$ and $50 \mu \mathrm{g}$ gentamicin $\mathrm{ml}^{-1}$. Escherichia coli strains were grown in Luria-Bertani (LB) broth at $37^{\circ} \mathrm{C}$ supplemented with the required antibiotics: $100 \mu \mathrm{g}$ ampicillin $\mathrm{ml}^{-1}, 25 \mu \mathrm{g}$ kanamycin $\mathrm{ml}^{-1}, 10 \mu \mathrm{g}$ tetracycline $\mathrm{ml}^{-1}$, $5 \mu \mathrm{g}$ gentamicin $\mathrm{ml}^{-1}$. For complementation studies, cells were grown overnight in GTS and then diluted in fresh GTS or GMS pH 4.8 medium to an $\mathrm{OD}_{600}$ of 0.1 . Growth was followed by reading $\mathrm{OD}_{600}$. The $\mathrm{pH}$ of the GMS broth after $24 \mathrm{~h}$ incubation remained below 5.1, a $\mathrm{pH}$ that does not allow growth of the mutant strain CIAT899-13T2. For UV induction experiments, cells were grown like those described for complementation studies to an $\mathrm{OD}_{600}$ of 0.3 ; $20 \mathrm{ml}$ aliquots of culture were withdrawn and laid on the bottom of a sterile Petri dish and gently agitated. This volume was enough to form a thin film that covered the bottom of the Petri dish. Cultures were then exposed to UV radiation for $30 \mathrm{~s}$ with a laminar-flow UV lamp (G30T8 Germicidal) and after that the culture was transferred to a flask for further incubation under the conditions applied before irradiation. Appropriate aliquots were sampled over time. Except for the irradiation time, throughout the experiment cells were kept in the dark.

DNA isolation and manipulations. Total genomic $R$. tropici DNA isolation, restriction enzyme digestion, ligation, plasmid isolation and Southern blotting experiments were carried out according to procedures described previously (Sambrook et al., 1989; Aguilar \& Grasso, 1991).

Cloning of the wild-type gshB gene region. A $R$. tropici CIAT899 partial genomic library, of fragments larger than $5 \mathrm{~kb}$, was constructed. Colony blotting was performed using Hybond-N+ membrane (Amersham Biosciences) according to the manufacturer's instructions. A R. tropici gshB 500 bp DNA fragment was amplified and labelled by PCR using specific primers PR13T2R3 (Riccillo et al., 2000) and Met (5'-CAACATTGCGGGTGATTCCAC- $\left.3^{\prime}\right)$, in the presence of $3.7 \times 10^{5} \mathrm{~Bq}\left[\alpha_{-}{ }^{32} \mathrm{P}\right] \mathrm{dATP} \quad\left(1.11 \times 10^{11} \mathrm{~Bq} \mathrm{mmol}^{-1}\right)$ (Amersham Biosciences) in the reaction mix, and used to probe the blots. A bacterial clone carrying a plasmid with a $7.5 \mathrm{~kb} R$. tropici DNA insert was confirmed to have the $g s h B$ gene region. The recombinant plasmid was named pCM1. The $7.5 \mathrm{~kb} R$. tropici DNA fragment from pCM1 was cloned in vector pSUP204, generating plasmid pCM2. A $3.2 \mathrm{~kb}$ XbaI-Sall fragment encompassing the $g s h B$ gene and ORF1 was subcloned from pCM2 into pSUP204 to yield plasmid pCM6.

Construction of a mutant strain in ORF1. An internal fragment of ORF1 was amplified with specific primers $418 \mathrm{~F}$
(5'-CCGGCAAAATAGGCGACATC- $3^{\prime}$ ) and 418R (5'-ATTGCATGGTCTTGAAACTGA-3'), using pCM1 as template DNA, and cloned in vector pGemT-Easy. The PCR fragment was then subcloned in plasmid pSUP102 and transferred by conjugation into strains $R$. tropici CIAT899 and CM11b. Single-event recombinants were selected in LB medium supplemented with tetracycline and alteration of the ORF1 sequence of these recombinants was confirmed by Southern blot analysis. Strain CM11b was constructed as follows. A BamHI fragment, which includes ORF1, was deleted from plasmid pCM11. This plasmid was used for conjugation into strain CIAT899 and single-event recombinants were selected.

RNA isolation and primer extension. Total RNA was isolated, using a phenol/chloroform/macaloid clay extraction as described by Raya et al. (1998); it was treated with RNase-free DNase (Promega) and repurified using TRIZOL reagent (Invitrogen), following the manufacturer's instructions. The quality of the RNA obtained was assessed by examining the integrity of rRNA bands in $0.8 \%$ agarose gels. For primer extension analysis, approximately $20 \mu \mathrm{g}$ RNA was mixed with the 33 base primer PrExt (5'-ATACCAGCCATAAGTCAGCCCTCGCTCGGATTT- $3^{\prime}$ ). This mixture was incubated at $85^{\circ} \mathrm{C}$ for $5 \mathrm{~min}$ and then cooled to $63^{\circ} \mathrm{C}$. After this annealing procedure, extension products were generated with the avian myeloblastosis virus reverse transcriptase (Promega). Products of the primer extension reactions were labelled by including $3.7 \times 10^{5} \mathrm{~Bq}\left[\alpha_{-}{ }^{32} \mathrm{P}\right] \mathrm{dATP}$ $\left(1.11 \times 10^{11} \mathrm{~Bq} \mathrm{mmol}^{-1}\right)$ in the extension mixture (Amersham Biosciences) and then they were separated on sequencing gels. The sequence reaction of the $5^{\prime}-g s h B$ region by using the primer PrExt was performed and the mixture was run side by side with the primer extension products.

Construction of gene fusions between gshB and lacz. The XbaI-SalI DNA fragment from pCM6 was cloned in pK18Mob. The resulting plasmid was digested with $X h o I$ and ligated to the lacZ-Gm cassette from plasmid pAB2001. The orientation of the inserted fragment was verified by restriction enzyme analysis. This plasmid was named pCM11. Plasmids were transferred to strain CIAT899 by conjugation, and transconjugants were selected on gentamicinsupplemented TY medium. Recombinants derived from the wildtype strain that resulted from a single crossover of plasmid pCM11 were named strain CM11. Plasmids containing the lacZ-Gm cassette inserted in a $3^{\prime}-5^{\prime}$ orientation with respect to $g s h B$ were also transferred to strain CIAT899 to use as controls.

Construction of fusions between the gshB promoter and lacZ. Two PCR fragments of $84 \mathrm{bp}$ and $152 \mathrm{bp}$ were cloned in vector plasmid pCR 2.1-TOPO. The $84 \mathrm{bp}$ fragment corresponds to the $5^{\prime}$-upstream region of $g s h B$ whereas the $152 \mathrm{bp}$ fragment extends further upstream from the $5^{\prime}$-end of the $84 \mathrm{bp}$ sequence to include the putative $g s h B$ promoter sequence described in this work. The primers used were forward primers F53 (5'-CTCGAGCAACTTCGTTCGGC-3') and F51 (5'-GCCTCTCGAGCAAACCTCC-3'), respectively, and the reverse primer R3 (5'-GGATTTGCCTCGAGATGTA$3^{\prime}$ ) (the underlined bases denote nucleotide positions that were changed in order to generate XhoI restriction sites). The identity of the cloned fragments was confirmed by sequencing analysis. The fragments were then excised with EcoRI and cloned in the EcoRI site of vector pMP220. The orientation of the inserts was checked by sequencing analysis. Finally, the plasmids containing the desired fusions were introduced by conjugative mating into strain CIAT899.

Site-directed mutagenesis. The sequence corresponding to the $5^{\prime}$-arm of the hairpin structure was replaced by a HindIII recognition site. This was achieved by megaprimer PCR mutagenesis as described by Tyagi et al. (2004) using the forward primer Mut (5'GCACACAGGGTAAGCTTGCTGAGTCG-3' ${ }^{\prime}$, where the underlined bases correspond to the introduced mutation) and primer Prom 3 to generate the mutation, and primers Prom53 and Prom3 to amplify a 
Table 1. Strains and plasmids used

\begin{tabular}{|c|c|c|}
\hline Strain & Relevant characteristics ${ }^{\star}$ & Reference \\
\hline E. coli $\mathrm{DH} 5 \alpha$ & supE44 $\Delta$ lacU169 ( $\phi 80$ lacZAM15) hsdR17 recA endA1 gyrA96 thi-1 relA1 & Hanahan (1983) \\
\hline E. coli $\mathrm{S} 17-1$ & $\begin{array}{l}\text { thi pro } h s d R^{-} h s d M^{+} \text {recA carrying RP4 2-Tc::Mu integrated in the } \\
\text { chromosome }\end{array}$ & Simon et al. (1983) \\
\hline \multicolumn{3}{|l|}{ R. tropici strains } \\
\hline CIAT899 & Sm, wild-type strain & Martínez-Romero et al. (1991) \\
\hline \multicolumn{3}{|c|}{ CIAT899 derivative strains } \\
\hline CIAT899-13T2 & Sm Nm, gshB:: Tn5-luxAB mutant & Riccillo et al. (2000) \\
\hline CM11 & Sm Gm, Nm, gshB-lac $Z$ transcriptional fusion & This work \\
\hline CM11b & Sm Gm Nm, same as CM11 with a unique copy of ORF1 & This work \\
\hline $\mathrm{CM} 20$ & Sm Tc, ORF1:pCM20 & This work \\
\hline CM21 & Sm Tc Gm Nm, gshB-lacZ transcriptional fusion, ORF1 : pCM20 & This work \\
\hline CM84D & Sm Tc, harbouring pCM84D & This work \\
\hline CM84L & Sm Tc, harbouring pCM84L & This work \\
\hline CM152D & Sm Tc, harbouring pCM152D & This work \\
\hline CM152L & Sm Tc, harbouring pCM152L & This work \\
\hline CIAT899MC18 & Sm Nm, guaB-lacZ transcriptional fusion & This laboratory \\
\hline CIAT899Mut & Sm Tc, harbouring pMut & This work \\
\hline CM15 & CIAT899-13T2 derivative strain with a $g s h B-l a c Z$ transcriptional fusion & This work \\
\hline \multicolumn{3}{|l|}{ Plasmids } \\
\hline pAB2001 & $\begin{array}{l}\text { Gm Ap, contains lacZ-Gm cassette used for the construction of } \\
\text { transcriptional fusions }\end{array}$ & Becker et al. (1995) \\
\hline pCM1 & Ap, pIC20H wild-type gshB $7.5 \mathrm{~kb}$ EcoRI fragment & This work \\
\hline pCM2 & Tc, pSUP104 with $7.5 \mathrm{~kb}$ EcoRI fragment from pCM1 & This work \\
\hline pCM6 & $\begin{array}{l}\text { Tc, pSUP104 with XbaI-SalI DNA fragment from pCM1 which } \\
\text { contains } g s h B \text { gene region }\end{array}$ & This work \\
\hline pCM19 & Ap, pGEM-T Easy with an ORF1 $350 \mathrm{bp}$ internal fragment & This work \\
\hline pCM20 & Tc, pSUP102 with an ORF1 350 bp internal fragment & This work \\
\hline pCM84D & $\begin{array}{l}\text { Tc, pMP220 derivative, containing an } 84 \text { bp fragment from upstream } \\
\text { gshB gene fused to lac } Z \text {, forming a transcriptional fusion }\end{array}$ & This work \\
\hline pCM84L & $\begin{array}{l}\text { Tc, pMP220 derivative, containing an } 84 \mathrm{bp} \text { fragment from upstream } \\
\text { gshB gene fused to lac } Z \text { in a } 3^{\prime} \text { - to } 5^{\prime} \text {-orientation, forming a } \\
\text { transcriptional fusion }\end{array}$ & This work \\
\hline pCM152D & $\begin{array}{l}\text { Tc, pMP220 derivative, containing a } 152 \text { bp fragment from upstream } \\
\text { gshB gene fused to lac } Z \text {, forming a transcriptional fusion }\end{array}$ & This work \\
\hline pCM152L & $\begin{array}{l}\text { Tc, pMP220 derivative, containing a } 152 \text { bp fragment from upstream } \\
\text { gsh } B \text { gene fused to lac } Z \text { in a } 3^{\prime}-5^{\prime} \text { orientation, forming a } \\
\text { transcriptional fusion }\end{array}$ & This work \\
\hline pCMMut & $\begin{array}{l}\text { Tc, pMP220 derivative, containing } 152 \text { bp Mut fragment fused to } \\
\text { lac } Z \text {, forming a transcriptional fusion }\end{array}$ & This work \\
\hline pCR 2.1-TOPO & Ap, cloning vector with $3^{\prime}-\mathrm{T}$ overhangs for cloning & Invitrogen Life Technologies \\
\hline pGEM-T Easy & Ap, vector with $3^{\prime}$-T overhangs for cloning & Promega \\
\hline $\mathrm{pIC} 20 \mathrm{H}$ & Ap, lac $Z$ vector with multiple cloning sites & Marsh et al. (1984) \\
\hline $\mathrm{pK} 18 \mathrm{Mob}$ & Km, pK18 derivative; mobilizable vector & Schafer et al. (1994) \\
\hline pMP220 & $\begin{array}{l}\text { Tc, appropriate replicative vector for constructing transcriptional } \\
\text { fusions in Rhizobium }\end{array}$ & Spaink et al. (1987) \\
\hline pSUP102 & Tc Cm, $\mathrm{Mob}^{+}$suicide vector in Rhizobium & Simon et al. (1986) \\
\hline pSUP104 & $\mathrm{Cm} \mathrm{Tc}, \mathrm{Mob}^{+}$broad-host-range pACYC184 derivative & Priefer et al. (1985) \\
\hline
\end{tabular}

${ }^{\star} \mathrm{Ap}, \mathrm{Km}, \mathrm{Gm}, \mathrm{Nm}, \mathrm{Sm}$ and Tc denote ampicillin, kanamycin, gentamicin, neomycin, streptomycin and tetracycline resistance, respectively.

152 bp mutated fragment (named Mut), which was cloned in TOPO 2.1 vector. The correct mutation was confirmed by DNA sequencing of the cloned fragment. The Mut fragment was then cloned in plasmid
pMP220 to create a transcriptional fusion between the Mut fragment and the lacZ sequence. This resulting plasmid (pCMMut) was introduced into strain CIAT899 as described above. 
Mobility-shift assays. $R$. tropici cells grown as described above were harvested at mid-exponential phase by centrifugation, washed and resuspended, as described by Schujman et al. (2003). Extracts were obtained with cells grown in GTS medium or with cells that had been harvested by centrifugation and resuspended in GMS medium for 10, 15,20 and $30 \mathrm{~min}$. The cells were lysed by sonication and the extracts were obtained by centrifugation at $8500 \mathrm{~g}$ for $10 \mathrm{~min}$ to remove large cell debris and unbroken cells. The supernatants were immediately frozen in liquid $\mathrm{N}_{2}$ and stored at $-80{ }^{\circ} \mathrm{C}$. Protein concentration was determined by using the bicinchoninic acid assay kit from SigmaAldrich. Probes were prepared by PCR amplification of the $152 \mathrm{bp}$, the $84 \mathrm{bp}$ and the Mut DNA fragments, respectively, in the presence of $3.7 \times 10^{5} \mathrm{~Bq}\left[\alpha_{-}{ }^{32} \mathrm{P}\right] \mathrm{dCTP}\left(1.11 \times 10^{11} \mathrm{~Bq} \mathrm{mmol}^{-1}\right.$ ) (Amersham Biosciences) in the reaction mix. Crude cell extracts (containing $150 \mu \mathrm{g}$ total protein) were incubated with the labelled DNA fragment for $15 \mathrm{~min}$ at room temperature in buffer A containing $16 \mu \mathrm{g}$ polydIdC ml ${ }^{-1}$ with the addition of $0.05 \%(\mathrm{v} / \mathrm{v})$ Nonidet P40 and $10 \mathrm{mM}$ $\mathrm{MgCl}_{2}$ as described by Shujman et al. (2003). The mixtures were separated by electrophoresis on $5 \%$ native polyacrylamide gels. The gels were dried and subjected to autoradiography. Alternatively, gels were stained with SYBR Green (Roche). For the competitive binding experiment, the incubation mix contained a 100-fold molar excess of either specific (the $152 \mathrm{bp}$ fragment) or non-specific (poly-dIdC) unlabelled competitor DNA. The shifted species was undetectable when experiments were run with 1000-fold dilution of whole cells extracts.

Quantitative determination of glutathione. Cellular glutathione content was determined by the method of Anderson (1985) using baker's yeast glutathione reductase (Sigma-Aldrich).

Biochemical assays. $\beta$-Galactosidase specific activity (Miller units: $\Delta A_{420} \min ^{-1}$ per ml culture $\times 1000 / \mathrm{OD}_{600}$ ) was assayed as described by Miller (1972). Cells were grown overnight in GTS medium, diluted in fresh GTS medium, and allowed to grow to an $\mathrm{OD}_{600}$ of 0.3 . Cells were harvested by centrifugation, resuspended in GMS medium $\mathrm{pH}$ 5.0, incubated at $28^{\circ} \mathrm{C}$ with agitation and sampled over time for $24 \mathrm{~h}$. In intracellular acidification studies, cells were grown as before, except that at $\mathrm{OD}_{600} 0.3$ the medium was supplemented with sodium acetate to a final concentration of $7 \mathrm{mM}$ and sampled over time. Effects of methylglyoxal, osmotic and oxidative challenges were assayed as described by Riccillo et al. (2000). All data shown represent the means of at least three replicate experiments. Assays were performed at least three times in independent experiments. Error bars represent standard deviations of replicate values obtained in an experiment. Data were analysed using Student's $t$-test with $P<0.05$.

Quantitative real-time reverse transcriptase PCR (qRT-PCR). RNA for reverse transcription was isolated from cells grown in GTS medium or cells that have been shifted to GMS medium and incubated for 10, 20, 30 and $60 \mathrm{~min}$. TRIZOL reagent (Invitrogen LifeTechnology) was used for RNA purification according to instructions provided by the manufacturer. Samples were treated with RNase-free DNase (Promega) for $30 \mathrm{~min}$ at $37^{\circ} \mathrm{C}$. DNase inactivation was done $10 \mathrm{~min}$ at $75^{\circ} \mathrm{C}$. Reverse transcription was carried out using Superscript II reverse transcriptase and specific primers, for $1 \mathrm{~h}$ at $42^{\circ} \mathrm{C}$. Quantitative PCR was carried out with $5 \mu \mathrm{l}$ of a $1 / 20$ dilution of the cDNA, by using a Platinum SYBR Green qPCR Supermix kit (Invitrogen). The primers used for PCR reactions were gshbFrt (5'-TCGTCACCGAATTTGCCGATCTCA-3') and gshbRrt (5'-ATTGCCGTAGAGCGGCTTCAGAAT- ${ }^{\prime}$ ). Denaturation of cDNA $\left(8 \mathrm{~min}\right.$ at $95^{\circ} \mathrm{C}$ ) and 45 cycles of denaturation, annealing and elongation were run on an iCycler real-time PCR system (Bio-Rad). Relative transcript abundance was calculated on the basis of a standard curve that was included. 16S rRNA was chosen as a reference for ratio normalization. Primers used for amplification of $16 \mathrm{~S}$ cDNA were 16SF (5'-AACGCATTAAACATTCCGCCTGGG-3') and 16SR $\left(5^{\prime}\right.$-TAACACAGGATGTCAAGGGCTGGT-3'). Every reaction was done at least twice.
DNA sequence analysis. Sequencing of double-stranded plasmid DNA was performed using the dideoxy method of Sanger, using the Sequenase kit (US Biochemicals). Nucleotide sequences were analysed by using programs CLUSTALW version 1.8.1 (Higgins, 1994) and BCM Search Launcher (http://searchlauncher.bcm.tmc.edu) (Smith et al., 1996; Worley et al., 1995, 1998). DNA two-dimensional structure was analysed using mfold (Zuker, 2003; http://www.bioinfo.rpi.edu/ applications/mfold/dna/form1.cgi). Algorithms available from server http://www.icgeb.trieste.it/dna were used to evaluate double helix stability parameters (Vlahovicek et al., 2003) as described by RamírezRomero et al. (2006).

\section{RESULTS}

\section{Cloning of the R. tropici CIAT899 gshB gene}

In order to clone the wild-type gshB gene, an EcoRI CIAT899 genomic library was probed with a gsh $B$ DNA fragment. This analysis resulted in the isolation of a $7.5 \mathrm{~kb}$ EcoRI DNA fragment, and an internal $3.2 \mathrm{~kb} X b a \mathrm{I}-$ Sall fragment was sequenced (GenBank accession no. DQ912168). Analysis of the sequence data revealed two ORFs, one of them corresponding to the gshB gene and the other, named ORF1, showing homology to a Rhizobium etli hypothetical protein (E-value of $10^{-60}$ ) (accession no. NC_007761.1, locus YP_467870, 11). The $3.2 \mathrm{~kb}$ fragment was then subcloned into plasmid pSUP204 to yield plasmid pCM6, which was transferred into the mutant strain CIAT899-13T2. Transconjugants were assessed for their glutathione content and growth under acidic conditions. The glutathione level of transconjugants $\left[85 \pm 5 \mathrm{nmol}(\mathrm{mg} \text { protein })^{-1}\right]$ was more than sixfold higher than that of the wild-type $[14 \pm 2 \mathrm{nmol}$ (mg protein $\left.)^{-1}\right]$. The transconjugants recovered the wildtype ability to grow in GMS medium at $\mathrm{pH} 4.8$ (data not shown), demonstrating that the cloned fragment contained a functional $g \operatorname{sh} B$.

In order to test whether ORF1 exerts an effect on the transcription of $g s h B$, we altered the ORF1 sequence in the wild-type strain $R$. tropici CIAT899, by constructing insertion mutants. Strain CM20, which represents one of these ORF1 mutants, was found to be tolerant to acid conditions as well as being phenotypically indistinguishable from the wild-type strain (results not shown). We also assayed $\beta$-galactosidase activity of strain CM11, which carries a gshB-lac $Z$ chromosomal transcriptional fusion, and strain CM21, which is isogenic to the former but carries a deletion within the ORF1 ( $\triangle \mathrm{ORF} 1, g s h B-$ lacZ). The level of $\beta$-galactosidase was comparable between these isogenic strains, having either the wild-type ORF1 or its mutant allele $(250 \pm 15$ and $245 \pm 15$ units for strain CM11 and CM21, respectively). These results indicate that transcription of $g \operatorname{sh} B$ is independent of the upstream ORF.

\section{Glutathione increases during acid shock}

We have previously shown that glutathione is important for acid tolerance in R. tropici (Riccillo et al., 2000); therefore the cellular glutathione content of CIAT899 subjected to acid stress was determined over time. This analysis showed 
Table 2. Effect of acid shock on the glutathione content of cells with multiple copies of gshB

Cells were grown to exponential phase in GTS medium and resuspended in GMS (pH 5) or GTS medium at time zero. Samples were periodically withdrawn, and their glutathione content was measured.

\begin{tabular}{|c|c|c|c|c|c|c|}
\hline \multirow{3}{*}{$\begin{array}{l}\text { Minutes after } \\
\text { acid shock }\end{array}$} & \multicolumn{6}{|c|}{ Cellular glutathione content [nmol glutathione $\left.(\mathrm{mg} \text { protein })^{-1}\right]$} \\
\hline & \multicolumn{2}{|c|}{ CIAT899 } & \multicolumn{2}{|c|}{ CIAT899(pCM6) } & \multicolumn{2}{|c|}{ CIAT899-13T2(pCM6) } \\
\hline & GTS & GMS & GTS & GMS & GTS & GMS \\
\hline 0 & $13 \pm 3$ & $13 \pm 3$ & $96 \pm 5$ & $94 \pm 4$ & $83 \pm 5$ & $80 \pm 3$ \\
\hline 30 & $10 \pm 2$ & $21 \pm 3$ & $95 \pm 4$ & $95 \pm 3$ & $85 \pm 5$ & $84 \pm 4$ \\
\hline 60 & $11 \pm 3$ & $26 \pm 2$ & $96 \pm 5$ & $91 \pm 5$ & $80 \pm 3$ & $82 \pm 5$ \\
\hline
\end{tabular}

that glutathione increased, about twofold, at $60 \mathrm{~min}$ (Table 2); it continued high for about $2 \mathrm{~h}$, after which cells recovered their basal levels (not shown).

This finding led us to investigate the effect of overexpressing $g s h B$ on the cellular level of glutathione in acid-stress conditions. Strains CIAT899(pCM6) and CIAT89913T2(pCM6), which containing $g s h B$ on the plasmid pCM6, which behaves as a multiple copy replicon, were assayed. The level of glutathione of the mutant strain was found to be seven times higher than that in the wild-type strain (Table 2). The glutathione content of the mutant was not affected by acid stress, indicating that the mechanism that leads glutathione to rise in acid conditions is tightly regulated.

\section{gshB transcription is induced by UV irradiation}

In order to test whether stresses other than acidity could be effectors of $g s h B$ expression, we examined the effect of UV radiation on $g s h B$ transcription. We measured $\beta$-galactosidase activity of strain CM11 immediately after UV exposure and found higher levels of $\beta$-galactosidase (Fig. 1). In order to assess the specificity of this response, we performed the same experiments with $R$. tropici CIAT899MC18, which has a guaB-lacZ chromosomal fusion. The guaB gene encodes the inosine monophosphate dehydrogenase enzyme required in the biosynthetic pathway of guanine. The $\beta$-galactosidase activity of strain CIAT899MC18 was unaffected by UV irradiation (Fig. 1), which demonstrates that the effect of UV irradiation is not a general cellular response. These results suggest that gshB is involved in the response to UV irradiation, and that glutathione may form part of the network that in $R$. tropici protects DNA from damage. Finally, we investigated whether $g \operatorname{sh} B$ transcription is affected by osmotic and oxidative stress, resistance to which is known to be mediated by glutathione (Riccillo et al., 2000). Our results showed no response of $g \operatorname{sh} B$ to these environmental constraints (data not shown).

\section{Activation of the R. tropici gshB gene by acidity}

In order to compare expression profiles of $g s h B$ under neutral and acidic conditions, we assayed the $\beta$-galactosidase activity of strain CM11. When strain CM11 was shifted to acidity, $\beta$-galactosidase activity increased - the peak of activity occurring 20-30 min after shifting - followed by a decrease to basal level (Fig. 2a). Sixty minutes after the shock, the level of $\beta$-galactosidase activity was similar to that detected in neutral growth medium. In addition, the same type of experiment was performed in a $g s h B$ genetic background by using strain CM15, which carries a chromosomal gshB-lacZ fusion. Under neutral growth conditions, the level of $g s h B$ transcription of the mutant strain was significantly higher than that of the wild-type strain, although the pattern of increase in response to acidity was similar in the two strains (data not shown). As in the case of UV irradiation, we performed a control experiment in which the same experimental treatment was applied to strain $R$. tropici CIAT899MC18 (guaB-lacZ fusion), and found that acidity had no effect on guaB transcription (Fig. 2a).

In order to confirm activation of $g s h B$ in response to acidic conditions, we used qRT-PCR to determine level of $g s h B$

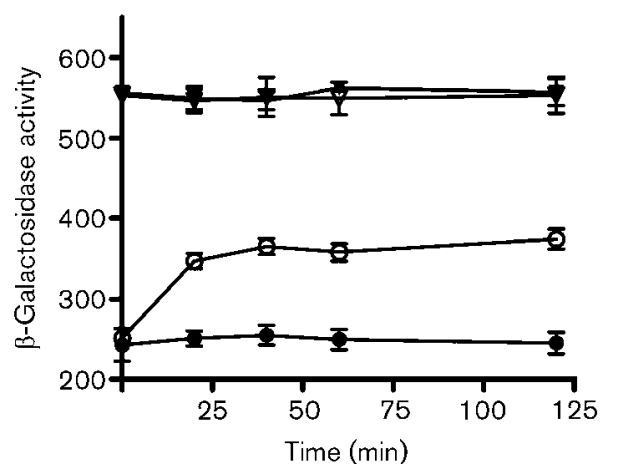

Fig. 1. Effect of UV irradiation on the transcription of the $R$. tropici gsh $B$ gene, determined as $\beta$-galactosidase activity of the gshB-lacZ fusion. $\beta$-Galactosidase activity (Miller units) by strain CM11 in UV irradiated $(\bigcirc)$ and non-irradiated $(\bullet)$ cultures was assayed. As a control the same experiment was performed with a strain carrying a guaB-lac $Z$ fusion; $\nabla$ and $\boldsymbol{\nabla}$ indicate $\beta$-galactosidase levels of irradiated and non-irradiated cells, respectively. Standard deviations are indicated as vertical bars. The $\beta$-galactosidase activity of cells of $\mathrm{CM} 11$ from irradiated and non-irradiated cultures of strain was significantly different $(P<0.05)$. 

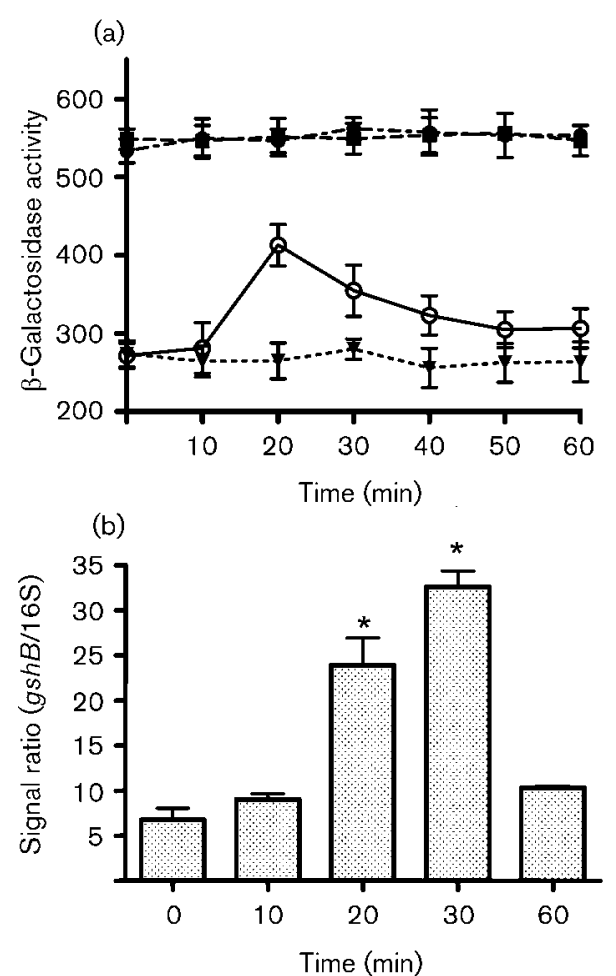

(c)

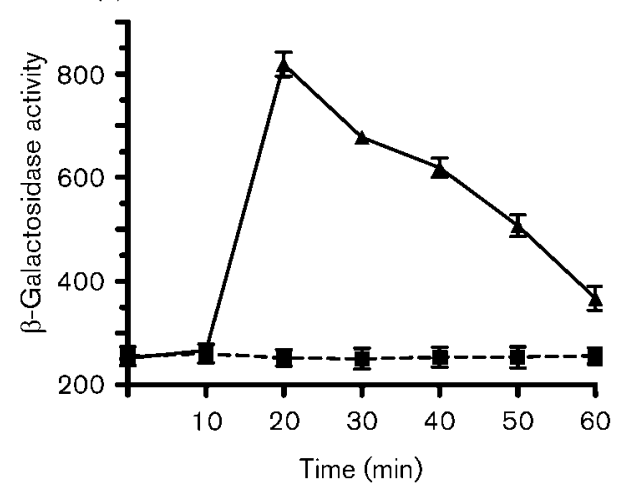

Fig. 2. Effect of acid stress on gshB expression. (a) $\beta$ Galactosidase activity (Miller units) in strains CM11 and CIAT899CM18, which were separately grown to exponential phase in GTS medium and resuspended in GMS medium $(\mathrm{pH} 5)$ at time zero ( $\bigcirc$ and $\bigcirc$, respectively); control samples were resuspended in GTS ( $\boldsymbol{\nabla}$ and $\boldsymbol{\square}$, respectively). (b) Expression level of $g s h B$ was measured by qRT-PCR in cells of strain CIAT899 that had been grown in GTS medium or that had been exposed to GMS medium ( $\mathrm{pH} \mathrm{5)}$ for 10, 20, 30 or $60 \mathrm{~min}$. Values were normalized to the constitutively expressed gene 16S rRNA. Asterisks on columns show values that were similar to each other, but significantly different from the rest $(P<0.05)$. (c) $\beta$-Galactosidase activity of strain $\mathrm{CM} 11$ grown as in (a) except that sodium acetate to a final concentration of $7 \mathrm{mM}$ was added at time zero $(\boldsymbol{\Delta})$. A control of untreated cells was included ( $\boldsymbol{\square})$. Standard deviations are indicated as vertical bars. The $\beta$-galactosidase activity of strain CM11 from GTS and GMS media (a) and from cells treated and not treated with sodium acetate (c) was significantly different $(P<0.05)$. transcript in wild-type cells incubated in neutral or in acidic medium. As shown in Fig. 2(b), acidity induced significant changes in $g s h B$ transcription. Twenty minutes after acidic exposure, the level of $g s h B$ transcript had increased about fivefold as compared to time zero. Levels decreased afterwards (Fig. 2b). This profile is consistent with the results obtained with the gshB-lacZ fusion.

We also measured $\beta$-galactosidase activity in cells incubated in the presence of sodium acetate, which produces intracellular acidification (Pérez-Galdona \& Kahn, 1994; Roe et al., 1998) and found that $R$. tropici displays a positive response similar to that found in conditions of external acidification, with a threefold increase (Fig. 2c). These results add further evidence that acid stress is an inducer of the $R$. tropici gshB gene.

The effect of exogenous glutathione on the acid responsiveness of $g s h B$ was also examined. $\beta$-Galactosidase activity of rhizobia that were grown in media supplemented with different concentrations of glutathione followed by acid shock was determined. Under these conditions, the degree of activation of $g s h B$ decreased as glutathione in the medium increased, in a dose-dependent manner, and was undetectable in cells incubated in medium containing above $0.8 \mathrm{mM}$ glutathione (data not shown). These findings indicate that exogenous glutathione overrides the $g s h B$ activation under acidic conditions. These results indicate that, in order to cope with acidity, $R$. tropici responds by raising its intracellular glutathione content, most likely by increasing the transcription of its biosynthetic genes.

\section{Analysis of the $5^{\prime}$-gshB upstream region}

It became evident from the preceding analysis that $g s h B$ is responsive to acid stress. Therefore, in order to characterize the $g s h B$ upstream region, we first determined the transcriptional initiation site by primer extension analysis using RNA template obtained from $R$. tropici CIAT899. As shown in Fig. 3(a), a signal was detected that corresponds to an adenine located 71 nucleotides upstream from the predicted translational start codon AUG. This upstream region was subjected to further analysis. Its comparison with the $\sigma^{70}$ promoter sequences of $S$. meliloti and $R$. etli described by MacLellan et al. (2006) and Ramírez-Romero et al. (2006), respectively, revealed a putative -35 box (CCTGAG) which contains four out of the six conserved bases of the canonical -35 sequence proposed in both reports. Located $14 \mathrm{bp}$ upstream of the transcription start site, a putative -10 element (CAAACC) was identified, which has only two and one conserved bases of the canonical -10 box described for S. meliloti and R. etli, respectively. Although this sequence has a very low level of conservation, this seems to be common also for $R$. etli and $S$. meliloti -10 boxes (MacLellan et al., 2006; Ramírez-Romero et al., 2006). We calculated the double helix-stability for this region, and found the value for the proposed -10 box to represent a minimum of local stability, which is in agreement with the overall characteristics shown for these -10 sequences by 


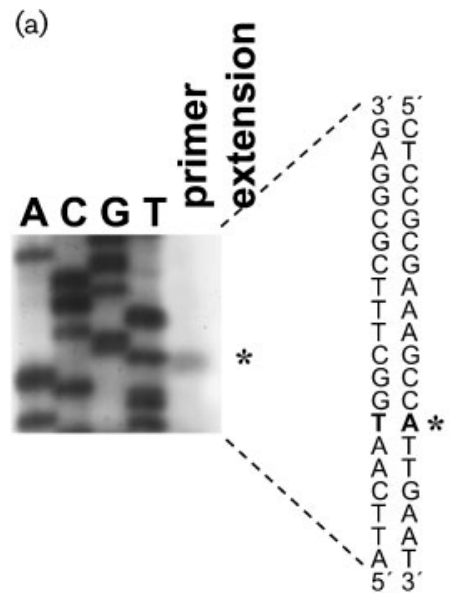

(b)

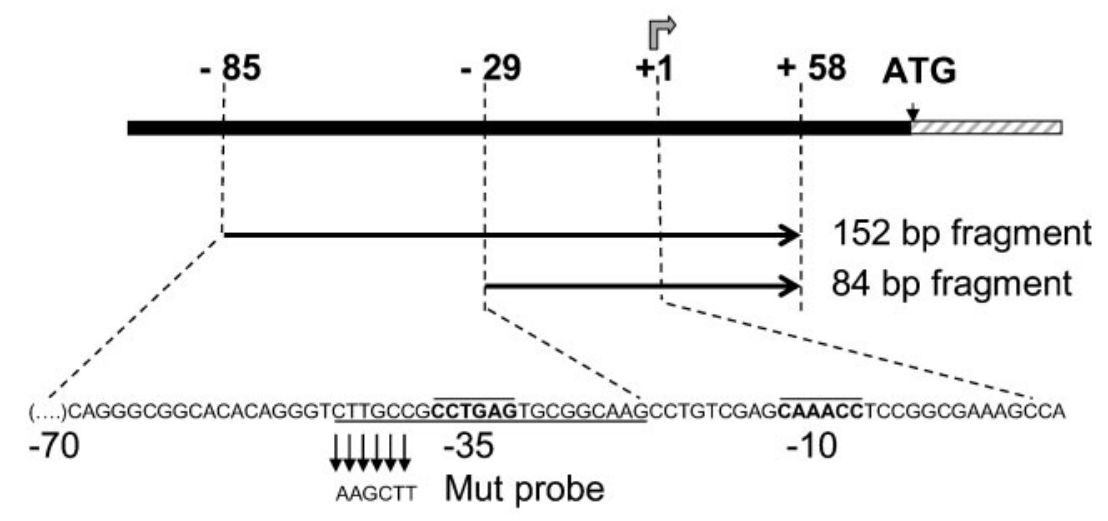

Fig. 3. Analysis of the $5^{\prime}$-gshB upstream region. (a) Primer extension analysis was performed to determine the $5^{\prime}$-end of the gshB transcript. Lanes A, C, G and T represent the DNA sequencing ladder. The transcriptional start point is indicated with an asterisk. (b) Schematic drawing of the upstream region of gshB. Fragments amplified for cloning (152 and $84 \mathrm{bp}$, respectively) or used as probes for the electrophoretic mobility-shift assays (152 and $84 \mathrm{bp}$, respectively) are shown with black arrows. Nucleotide positions are numbered relative to the transcription start site. The transcription start site is indicated with a grey arrow $(+1)$. The hairpin structure mentioned in the text is underlined. The -35 and -10 elements are indicated in bold type and overlined. The sequence that was mutated in order to generate Mut probe is shown below the corresponding modified bases.

Ramírez-Romero et al. (2006). The features found in the $5^{\prime}$-region of $g s h B$ indicate that the basal expression we detected in our assays may take place from a $\sigma^{70}$ promoter element. Further experiments are needed to test this possibility.

Further analysis of the $g s h B$ upstream region was performed by using the mfold DNA web server (Zuker, 2003), which facilitates identification of potential secondary structures. Thus, a hairpin structure with an estimated value of $\Delta G$ approx. $-9 \mathrm{kcal} \mathrm{mol}^{-1}\left(-38 \mathrm{~kJ} \mathrm{~mol}^{-1}\right)$ was detected between positions -28 and -50 (Fig. $3 \mathrm{~b}$ ). Inspection of this region revealed an 8 bp inverted repeat, which contains the sequence CTTGCCGCN 6 GCGGCAAG. The observation that this dyad structure and the predicted -35 box share part of the $5^{\prime}$-gshB upstream region suggested its involvement in $g s h B$ regulation.

In order to assess the significance of the putative promoter elements for the $g s h B$ expression, we next applied a functional approach. Thus, two DNA fragments of $84 \mathrm{bp}$ and $152 \mathrm{bp}$ each spanning part of the $g s h B$ upstream region were individually cloned to construct transcriptional fusions to the lac $Z$ gene. These two fragments share their $3^{\prime}$-end at nucleotide +58 , which fuses to the $l a c Z$ gene, whereas they differ in the $5^{\prime}$-end at positions -29 and -85 (Fig. 3b). In this way, plasmid pCM152D but not pCM84D carries the putative regulatory elements that were described above. These plasmids were transferred to $R$. tropici CIAT899 and the transconjugants obtained were used to determine $\beta$-galactosidase activity in GTS-grown cells (Fig. 4a). Significant activity was detected in cells carrying pCM152D whereas basal level of activity was detected with pCM84D. In addition, $\beta$-galactosidase activity produced by pCM152D was quantified in GTS-grown cells after exposure to GMS acid medium. After $20 \mathrm{~min}$ of acid exposure, $\beta$-galactosidase increased about threefold above the background level (Fig. 4b). These results indicate that the upstream sequence includes signals within the $152 \mathrm{bp}$ fragment, needed for $g \mathrm{sh} B$ to show an acid response.

\section{Investigation of the protein-binding ability of the gshB promoter}

The evidence described above, which indicated activation of the $g s h B$ promoter under acidic conditions, prompted us to investigate whether cell-free extracts from acid-treated $R$. tropici CIAT899 may contain proteins that bind to the promoter sequence. In order to examine this possibility, we performed gel mobility-shift assays.

The radioactive labelled $152 \mathrm{bp}$ DNA fragment containing the promoter sequence was incubated with cell extracts of $R$. tropici CIAT899 grown in neutral and in acid media, and samples of each of these mixtures were then run on a polyacrylamide gel. The probe incubated with extracts obtained from neutral medium migrated similarly to the free probe. By contrast, a retardation band was observed with the extracts obtained from acid-treated cells. The retardation band was detectable by using extracts from cells that had been acid shifted for 10, 15, 20 and $30 \mathrm{~min}$ (Fig. 5a). This species was resistant to competition by excess of non-specific DNA (100-fold by weight), but not when the $152 \mathrm{bp}$ fragment was used as competitor (data not shown). 
(a)

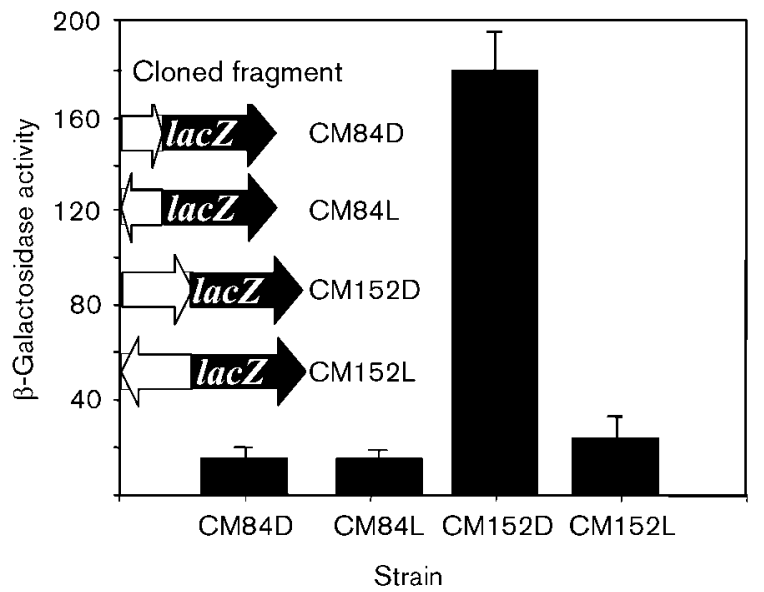

(b)

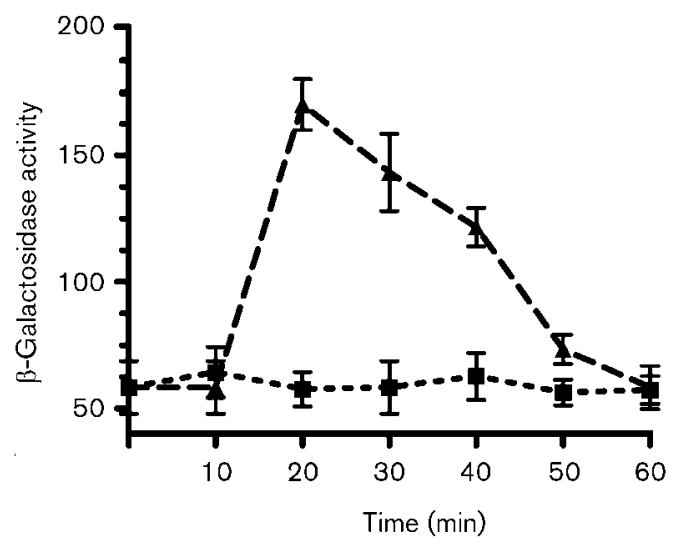

Fig. 4. Functional analysis of the gshB upstream region. (a) Levels of $\beta$-galactosidase activity (Miller units) were assayed for strains carrying lacZ fused to a $152 \mathrm{bp}$ (CM152D) or $84 \mathrm{bp}$ (CM84D) DNA fragment of the gshB upstream region. Strains $\mathrm{CM} 152 \mathrm{~L}$ and $\mathrm{CM} 84 \mathrm{~L}$ carrying respectively the same regions fused to lac $Z$ in a $3^{\prime}-5^{\prime}$ orientation were also assayed. The black arrow represents the lac $Z$ gene, the white arrow the fused fragment. (b) Cells of strain CM152D were grown to exponential phase in GTS medium and resuspended in GMS $(\mathrm{pH} 5)$ at time zero; $\beta$-galactosidase activity was determined over time (A). Control samples were resuspended in GTS (ם). Standard deviations are indicated as vertical lines. The $\beta$-galactosidase activity of strain CM152D in GTS and GMS media was significantly different $(P<0.05)$.

We also assayed protein-binding ability of the $84 \mathrm{bp}$ fragment described above, which was incubated with cell extracts from $R$. tropici CIAT899 grown in neutral media, and from cells that had been shifted and incubated for $20 \mathrm{~min}$ in acid media. The $152 \mathrm{bp}$ fragment was included as a control. The results of these experiments are shown in Fig. 5(b). The $84 \mathrm{bp}$ fragment migrated equally with extracts from either neutral or acid-treated cells, and it was indistinguishable from that of the free probe.

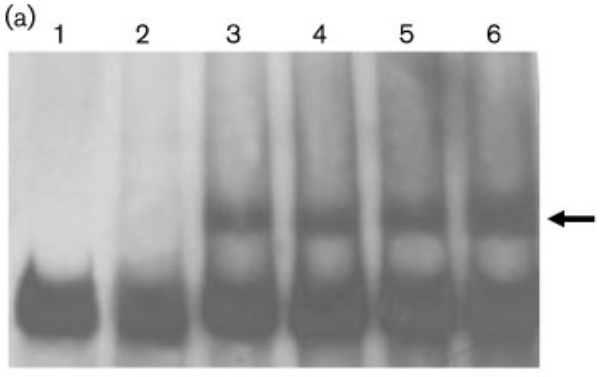

(b)

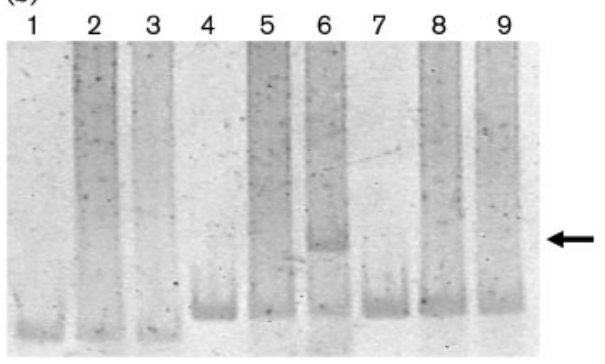

Fig. 5. Gel mobility-shift assays with the R. tropici gshB promoter. (a) The 152 bp DNA probe, which was labelled with $\left[{ }^{32} \mathrm{P}\right] \mathrm{dCTP}$, was incubated with cell extracts prepared from GTS medium (lane 2) and from cells that had been resuspended in GMS medium ( $\mathrm{pH} 5$ ) and incubated for 10, 15, 20 and $30 \mathrm{~min}$, respectively (lanes 3-6). The migration of the free probe is shown in lane 1. (b) The DNA fragments were incubated with lysates prepared from cells grown in GTS medium (lanes 2, 5 and 8, for the 84, $152 \mathrm{bp}$ and Mut fragments, respectively) and from cells that had been acid-shifted for 20 min (lanes 3, 6 and 9, for the 84, 152 bp and Mut fragments, respectively). The migration of the free probe incubated in the absence of cell extract is shown in lanes 1 (84 bp fragment), 4 (152 bp fragment) and 7 (Mut fragment). The gel was SYBR Green stained. The arrows indicate the retardation species described in the text.

In order to assess the importance of the imperfect inverted repeat for the formation of the 152 bp DNA fragmentprotein complex we have detected, the inverted repeat was altered. The $5^{\prime}$-arm of the repeat was replaced by a HindIII restriction site, which prevents formation of the secondary structure, although it should be noted that the mutation does not alter the -35 box (Fig. 3b). The mutant fragment obtained was named Mut. Retardation assays were performed by using the Mut fragment as a probe. No DNA-protein complexes were detectable in this case (Fig. 5b).

In addition, the effect of the mutation was assessed by in vivo experiments. The Mut fragment was also cloned in plasmid pMP220 to construct a Mut-lacZ transcriptional fusion, generating plasmid pCMMut, which was transferred by conjugation to strain CIAT899. We compared the $\beta$ galactosidase activity produced by cells containing the mutant plasmid pCMMut or the wild-type plasmid pCM152. Under conditions of neutral growth, we found no differences between plasmids pCMMut and pCM152. 
However, $\beta$-galactosidase activity of cells carrying the wildtype plasmid pCM152, unlike the mutant pCMMut, was found to increase when cells were transferred to acid medium (data not shown), which demonstrated that integrity of the inverted repeat is needed in order to promote transcription under acidic conditions.

These results indicated that extracts of acid-treated cells contain protein(s) that bind the upstream region of $g s h B$ and that in order to show protein-binding properties, the integrity of the 8 bp inverted repeat is required. From our results with the transcriptional fusions, we propose this element to play a role in regulation of $g s h B$ expression in response to acidity.

\section{DISCUSSION}

In a previous report, we demonstrated that $g s h B$ is important for acid tolerance in $R$. tropici (Riccillo et al., 2000). It was proposed that glutathione may play a role in controlling the $\mathrm{K}^{+}$flux and therefore enable cells to achieve the intracellular potassium levels needed to survive in low-pH environments (Ferguson \& Booth, 1998; Riccillo et al., 2000; Masip et al., 2006). Without glutathione either produced by its own biosynthetic metabolism or supplied externally, $R$. tropici is unable to grow under acidic conditions. In this work, we present data on the regulation of the expression of the $R$. tropici gshB gene. Our results provide evidence that the intracellular level of glutathione is increased in response to low $\mathrm{pH}$ by a mechanism that involves the transcriptional activation of the $g s h B$ gene. Furthermore, if glutathione is supplied in the culture medium or alternatively overproduced from a $g s h B$ gene carried on a multicopy plasmid, there is no detectable effect of acidity on $g s h B$ transcription, suggesting that from this point of view the level of available glutathione is enough to overcome acid shock. These results reinforce the idea that glutathione participates in acid resistance in $R$. tropici.

Generally, the mechanisms microbes have to overcome acidity are known as acid resistance (AR), which has mainly been investigated in E. coli. In Rhizobium, several genes have been characterized as essential for AR (Tiwari et al., 1996a, b; Riccillo et al., 2000; Vinuesa et al., 2003; Rojas-Jiménez et al., 2005; Reeve et al., 2006). Genes involved in $\mathrm{CO}_{2}$ fixation, hydantoin utilization and microaerobic respiration have been found in Sinorhizobium medicae to be regulated by the acid-sensitive ActS/ActR regulatory system (Fenner et al., 2004). By using a transcriptome approach, Tiwari et al. (2004) have reported genes of $S$. medicae to be induced about $2-25$-fold by shifting the $\mathrm{pH}$ from 7.0 to 5.7 . By applying alternative experimental procedures to determine transcriptional activity, namely gene fusion to lac $Z$ and quantitative PCR, we have shown $g s h B$ transcription to increase under acidic conditions. It should be noted that $\beta$-galactosidase activation under acidic conditions was detectable at a lower level than that determined by qRTPCR and that it declined after $1 \mathrm{~h}$ of exposure to acidity. We have no explanation for this phase of decline that follows activation, as the $\beta$-galactosidase protein should be expected to be stable. Taking these results altogether, it is possible to conclude that a small increase in the pattern of expression is still important to compensate environmental constraints. This observation suggests that following the acid shock in which early responses such as that of glutathione are detectable, other mechanisms may participate. Given the role of glutathione in acid tolerance and acid responsiveness, it is clear that $g s h B$ is an additional gene participating in the AR of $R$. tropici. Although several authors have shown the complex nature of the response caused by acidity, we believe this is the first report demonstrating the involvement of glutathione biosynthetic genes in such a response.

We found that $g s h B$ is induced by UV irradiation. Glutathione has previously been shown to be related to protection against UV irradiation, apparently by means of scavenging the ROS generated (Masip et al., 2006). Glutathione has also been involved in the modulation of the hydrogen peroxide-induced transcriptional activator OxyR, which may in turn protect against UV-induced oxidative stress (Masip et al., 2006). In E. coli, glutathione reductase levels have been demonstrated to be enhanced after a low UV dose (Hoerter et al., 2005). Although the R. tropici gshB mutant showed survival rates after UV exposure similar to those of the wild-type strain (data not shown), this may reflect the fact that mutants in the glutathione synthetase gene usually show high levels of $\gamma$-glutamylcysteine, the biosynthetic precursor of glutathione, which has also been proposed to act as an antioxidant (Harrison et al., 2005). Nevertheless, our data showing that $g s h B$ transcription increases after exposure to UV suggest that this gene could be part of the $R$. tropici SOS response (O'Reilly \& Kreuzer, 2004).

The responsiveness of $g s h B$ to acidity led us to characterize its $5^{\prime}$-upstream sequence. Generally, prokaryotic transcriptional activation requires sites for binding the RNA polymerase and activators, which aligned at the promoter, interact with each other. We have identified a $152 \mathrm{bp}$ fragment with promoter activity which is implied in $g \operatorname{sh} B$ acid responsiveness. By sequence comparison, a putative $\sigma^{70}$ has been identified within the $152 \mathrm{bp}$ of the $5^{\prime}$-upstream region, which also overlaps a dyad symmetrical element. This fragment forms a stable DNA-protein complex with proteins present in extracts of acid-treated cells. The importance of this inverted repeat sequence is evidenced by the drastic negative effect that its alteration has on the protein-binding properties as well on the gsh $B$ activation after acid stress. These results indicate that the hairpin sequence we have identified is a key element in the gshB acid response. Although the understanding of the mechanisms by which $g s h B$ expression is controlled is still incomplete, we believe our data provide strong evidence of its regulation by acidity, and we speculate that under normal neutral media conditions, transcription takes places from the $\sigma^{70}$ promoter whereas under acidic conditions the inverted repeat 
element is important for $g s h B$ expression. Certainly, further experiments are needed to demonstrate this mechanism. Transcriptional activators that participate in the acid response were not identified in S. meliloti and S. medicae after extensive studies by Reeve et al. (2002) and Tiwari et al. (2004). More recently, Reeve et al. (2006) have described the trancriptional activation of gene lpiA of $S$. medicae by FsrR, which is involved in acidic conditions. In addition, positive regulation in other micro-organisms has been reported such as that of the two-component system ArsRS in up-regulating some genes of Helicobacter pylori (Pflock et al., 2006).

Summarizing, we have found that glutathione is essential for $R$. tropici to grow at low $\mathrm{pH}$ and that expression of acid tolerance involves transcriptional activation of the $g s h B$ gene in which protein (s) binds the $5^{\prime}$-upstream region, a feature in which inverted repeat sequences appear to be important. We are currently pursuing the identification of proteins present in acid-treated cells that have a regulatory role in gshB expression.

\section{ACKNOWLEDGEMENTS}

This work was supported by grants from Agencia de Promoción Científica y Tecnológica, Argentina (PICT no. 7072/99) and Consejo Nacional de Investigaciones Científicas y Tecnológicas-CONICET, Argentina. O.M.A. and C.I.M. were supported by CONICET, Argentina. The authors would like to thank Mónica Collavino for providing strain CIAT899MC18, Herman Spaink and Angeles Zorreguieta for providing plasmid pMP220, and Pablo Riccillo for the $R$. tropici CIAT899-13T2 strain and for the $3.2 \mathrm{~kb} E c o$ RI-fragment sequence. C. I. M. would like to thank Gustavo Schujman for his help with the mobility-shift assays.

\section{REFERENCES}

Aguilar, O. M. \& Grasso, D. H. (1991). The product of the Rhizobium meliloti ilvC gene is required for isoleucine and valine synthesis and nodulation of alfalfa. J Bacteriol 173, 7756-7764.

Allocati, N., Favaloro, B., Masulli, M., Alexeyev, M. D. \& Di Ilio, C. (2003). Proteus mirabilis glutathione $S$-transferase B1-1 is involved in protective mechanisms against oxidative and chemical stresses. Biochem J 373, 305-311.

Anderson, M. E. (1985). Determination of glutathione and glutathione disulfide in biological samples. Methods Enzymol 113, 548-555.

Becker, A., Schmidt, M., Jäger, W. \& Pühler, A. (1995). New gentamicin-resistance and lacZ promoter probe for insertion mutagenesis and generation of transcriptional fusions. Gene 162, 37-39.

Beringer, J. E. (1974). R factor transfer in Rhizobium leguminosarum. J Gen Microbiol 84, 188-198.

Carmel-Harel, O. \& Storz, G. (2000). Roles of glutathione- and thioredoxin-dependent reduction systems in the Escherichia coli and Saccharomyces cerevisiae responses to oxidative stress. Annu Rev Microbiol 54, 439-461.

Dombrecht, B., Heusdens, H., Beullens, S., Verreth, C., Mulkers, E., Proost, P., Vanderleyden, J. \& Michiels, J. (2005). Defense of Rhizobium etli bacteroids against oxidative stress involves a complexly regulated atypical 2-Cys peroxiredoxin. Mol Microbiol 55, 1207-1221.
Escudero, P. R., Minchin, F. R., Gogorcena, Y., Iturbe-Ormaetxe, I., Klucas, R. V. \& Becana, M. (1996). Involvement of activated oxygen in nitrate-induced senescence of pea root nodules. Plant Physiol 110, 1187-1195.

Fenner, B. J., Tiwari, R. P., Reeve, W. J., Dilworth, M. J. \& Glenn, A. R. (2004). Sinorhizobium medicae genes whose regulation involves the ActS and/or ActR signal transduction proteins. FEMS Microbiol Lett 236, 21-31.

Ferguson, G. P. \& Booth, I. R. (1998). Importance of glutathione for growth and survival of Escherichia coli cells: detoxification of methylglyoxal and maintenance of intracellular $\mathrm{K}^{+}$. J Bacteriol 180, 4314-4318.

Hanahan, D. (1983). Studies on transformation of Escherichia coli with plasmids. J Mol Biol 166, 557-580.

Harrison, J., Jamet, A., Muglia, C., Van de Sype, G., Aguilar, O. M., Puppo, A. \& Frendo, P. (2005). Glutathione plays a fundamental role in growth and symbiotic capacity of Sinorhizobium meliloti. J Bacteriol 187, 168-174.

Higgins, D. G. (1994). CLUSTAL V: multiple alignment of DNA and protein sequences. Methods Mol Biol 25, 307-318.

Hoerter, J. D., Arnold, A. A., Kuczynska, D. A., Shibuya, A., Ward, C. S., Sauer, M. G., Gizachew, A., Hotchkiss, T. M., Fleming, T. J. \& Johnson, S. (2005). Effect of sublethal UVA irradiation on activity levels of oxidative defence enzymes and protein oxidation in Escherichia coli. J Photochem Photobiol B 81, 171-180.

Iturbe-Ormaetxe, I., Matamoros, M. A., Rubio, M. C., Dalton, D. A. \& Becana, M. (2001). The antioxidants of legume root nodule mitochondria. Mol Plant Microbe Interact 14, 1189-1196.

Jamet, A., Sigaud, S., Van de Sype, G., Puppo, A. \& Herouart, D. (2003). Expression of the bacterial catalase genes during Sinorhizobium meliloti-Medicago sativa symbiosis and their crucial role during the infection process. Mol Plant Microbe Interact 16, 217-225.

Kiss, G., Vincze, Ė., Kálman, Z., Forrai, T. \& Kondorosi, Á. (1979). Genetic and biochemical analysis of mutants affects nitrate reduction in Rhizobium meliloti. J Gen Microbiol 113, 105-118.

Lillig, C. H., Potamitou, A., Schwenn, J. D., Vlamis-Gardikas, A. \& Holmgren, A. (2003). Redox regulation of $3^{\prime}$-phosphoadenylylsulfate reductase from Escherichia coli by glutathione and glutaredoxins. J Biol Chem 278, 22325-22330.

MacLellan, S. R., MacLean, A. M. \& Finan, T. M. (2006). Promoter prediction in the rhizobia. Microbiology 152, 1751-1763.

Marsh, J. L., Erfle, M. P. \& Wykes, E. J. (1984). The pIC plasmid and phage vectors with versatile cloning sites for recombinant selection by insertional inactivation. Gene 32, 481-485.

Martínez-Romero, E., Segovia, L., Mercante, F. M., Franco, A. A., Graham, P. \& Pardo, M. A. (1991). Rhizobium tropici, a novel species nodulating Phaseolus vulgaris beans and Leucaena sp. trees. Int J Syst Bacteriol 41, 417-426.

Masip, L., Veeravalli, K. \& Georgiou, G. (2006). The many faces of glutathione in bacteria. Antioxid Redox Signal 8, 753-762.

Matamoros, M. A., Baird, L. M., Escudero, P. R., Dalton, D. A., Minchin, F. R., Iturbe-Ormaetxe, I., Rubio, M. C., Morán, J. F., Gordon, A. J. \& Becana, M. (1999). Stress-induced legume root nodule senescence. Physiological, biochemical and structural alterations. Plant Physiol 121, 97-111.

Matamoros, M. A., Dalton, D. A., Ramos, J., Clemente, M. R., Rubio, M. C. \& Becana, M. (2003). Biochemistry and molecular biology of antioxidants in the rhizobia-legume symbiosis. Plant Physiol 133, 499-509.

Miller, J. (1972). Experiments in Molecular Genetics. Cold Spring Harbor, NY: Cold Spring Harbor Laboratory.

Moran, J. F., Iturbe-Ormaetxe, I., Matamoros, M., Rubio, M. C., Clemente, M. R., Brewin, N. J. \& Becana, M. (2000). Glutathione and 
homoglutathione synthetases of legume nodules. Cloning, expression, and subcellular localization. Plant Physiol 124, 1381-1392.

Neumann, C., Boubakari, Grunert, R. \& Bednarski, P. J. (2003). Nicotinamide adenine dinucleotide phosphate-regenerating system coupled to a glutathione-reductase microtiter method for determination of total glutathione concentrations in adherent growing cancer cell lines. Anal Biochem 320, 170-178.

Noctor, G., Gómez, L. D., Vanacker, H. \& Foyer, C. H. (2002). Interactions between biosynthesis, compartmentation and transport in the control of glutathione homeostasis and signalling. J Exp Bot 53, 1283-1304.

O’Reilly, E. K. \& Kreuzer, K. N. (2004). Isolation of SOS constitutive mutants of Escherichia coli. J Bacteriol 186, 7149-7160.

Penninckx, M. J. \& Elskens, M. T. (1993). Metabolism and functions of glutathione in micro-organisms. Adv Microb Physiol 34, 239-301.

Pérez-Galdona, R. \& Kahn, M. L. (1994). Effects of organic acids and low pH on Rhizobium meliloti 104A14. Microbiology 140, 1231-1235.

Pflock, M., Finsterer, N., Joseph, B., Mollenkopf, H., Meyer, T. F. \& Beier, D. J. (2006). Characterization of the ArsRS regulon of Helicobacter pylori, involved in acid adaptation. J Bacteriol 188, 3449-3462.

Priefer, U. B., Simon, R. \& Pühler, A. (1985). Extension of the host range of Escherichia coli vectors by incorporation of RSF1010 replication and mobilization functions. J Bacteriol 163, 324-330.

Pühler, A. \& Timmis, K. (editors) (1984). Advanced Molecular Genetics. Berlin: Springer.

Ramírez-Romero, M. A., Masulis, I., Cevallos, M. A., González, V. \& Dávila, G. (2006). The Rhizobium etli sigma70 (SigA) factor recognizes a lax consensus promoter. Nucleic Acids Res 34, 1470-1480.

Raya, R., Bardowski, J., Andersen, P. S., Erlich, S. D. \& Chopin, A. (1998). Multiple transcriptional control of the Lactococcus lactis $\operatorname{trp}$ operon. J Bacteriol 180, 3174-3180.

Reeve, W. G., Tiwari, R. P., Kale, N. B., Dilworth, M. J. \& Glenn, A. R. (2002). ActP controls copper homeostasis in Rhizobium leguminosarum bv. viciae and Sinorhizobium meliloti preventing low $\mathrm{pH}-$ induced copper toxicity. Mol Microbiol 43, 981-991.

Reeve, W. G., Bräu, L., Castelli, J., Garau, G., Sohlenkamp, C. Geiger, O., Dilworth, M. J., Glenn, A. R., Howieson, J. G. \& Tiwari, R. P. (2006). The Sinorhizobium medicae WSM419 lpiA gene is transcriptionally activated by FsrR and required to enhance survival in lethal acid conditions. Microbiology 152, 3049-3059.

Riccillo, P. M., Muglia, C., De Bruijn, F. J., Roe, A., Booth, I. R. \& Aguilar, O. M. (2000). Glutathione is involved in environmental stress responses in Rhizobium tropici, including acid tolerance. J Bacteriol 182, 1748-1753.

Roe, A. J., McLaggan, D., Davidson, I., O'Byrne, C. \& Booth, I. R. (1998). Perturbation of anion balance during inhibition of growth of Escherichia coli by weak acids. J Bacteriol 180, 767-772.

Rojas-Jiménez, K., Sohlenkamp, K., Geiger, O., Martínez-Romero, E., Werner, D. \& Vinuesa, P. (2005). A ClC chloride channel homolog and ornithine-containing membrane lipids of Rhizobium tropici CIAT899 are involved in symbiotic efficiency and acid tolerance. Mol Plant Microbe Interact 18, 1175-1185.

Sambrook, J., Fritsch, E. \& Maniatis, T. (1989). Molecular Cloning: a Laboratory Manual, 2nd edn. Cold Spring Harbor, NY: Cold Spring Harbor Laboratory.

Santos, R., Herouart, D., Puppo, A. \& Touati, D. (2000). Critical protective role of bacterial superoxide dismutase in Rhizobiumlegume symbiosis. Mol Microbiol 38, 750-759.
Schafer, A., Tauch, A., Jager, W., Kalinowski, J., Thierbach, G. \& Pühler, A. (1994). Small mobilizable multi-purpose cloning vectors derived from the Escherichia coli plasmids pK18 and pK19: selection of defined deletions in the chromosome of Corynebacterium glutamicum. Gene 145, 69-73.

Schujman, G. E., Paoletti, L., Grossman, A. D. \& de Mendoza, D. (2003). FapR, a bacterial transcription factor involved in global regulation of membrane lipid biosynthesis. Dev Cell 4, 663-672.

Sherrill, C. \& Fahey, R. C. (1998). Import and metabolism of glutathione by Streptococcus mutans. J Bacteriol 180, 1454-1459.

Sigaud, S., Becquet, V., Frendo, P., Puppo, A. \& Herouart, D. (1999). Differential regulation of two divergent Sinorhizobium meliloti genes for HPII-like catalases during free-living growth and protective role of both catalases during symbiosis. J Bacteriol 181, 2634-2639.

Simon, R., Priefer, U. \& Pühler, A. (1983). A broad host range mobilization system for in vivo genetic engineering: transposon mutagenesis in gram negative bacteria. BioTechnology 1, 784-791.

Simon, R., O'Connell, M., Labes, M. \& Pühler, A. (1986). Plasmid vectors for the genetic analysis and manipulation of rhizobia and other gram-negative bacteria. Methods Enzymol 118, 640-659.

Smith, R. F., Wiese, B. A., Wojzynski, M. K., Davison, D. B. \& Worley, K. C. (1996). BCM search launcher - an integrated interface to molecular biology data base search and analysis services available on the world wide web. Genome Res 6, 454-462.

Spaink, H. P., Okker, R. J., Wijffelman, C. A., Pees, E. \& Lugtenberg, B. J. (1987). Promoters in the nodulation region of the Rhizobium leguminosarum sym plasmid pRL1JI. Plant Mol Biol 9, 27-39.

Tiwari, R. P., Reeve, W. G., Dilworth, M. J. \& Glenn, A. R. (1996a). An essential role for actA in acid tolerance in Rhizobium meliloti. Microbiology 142, 601-602.

Tiwari, R. P., Reeve, W. G., Dilworth, M. J. \& Glenn, A. R. (1996b). Acid tolerance in Rhizobium meliloti strain WSM419 involves a twocomponent sensor-regulator system. Microbiology 142, 1693-1704.

Tiwari, R. P., Reeve, W. G., Fenner, B. J., Glenn, A. R. \& Howeison, J. G. (2004). Probing for pH-regulated genes in Sinorhizobium medicae using transcriptional analysis. J Mol Microbiol Biotechnol 7, 133-139.

Tyagi, R., Lai, R. \& Duggleby, R. G. (2004). A new approach to 'megaprimer' polymerase chain reaction mutagenesis without an intermediate gel purification step. BMC Biotechnol 4, 2.

Vinuesa, P., Neumann-Silkow, F., Pacios-Bras, C., Spaink, H. P., Martínez-Romero, E. \& Werner, D. (2003). Genetic analysis of a pHregulated operon from Rhizobium tropici CIAT899 involved in acid tolerance and nodulation competitiveness. Mol Plant Microbe Interact 16, 159-168.

Vlahovicek, K., Kajan, L. \& Pongor, S. (2003). DNA analysis servers: plot.it, bend.it, model.it and IS. Nucleic Acids Res 31, 3686-3687.

Worley, K. C., Wiese, B. A. \& Smith, R. F. (1995). BEAUTY: an enhanced BLAST-based search tool that integrates multiple biological information resources into sequence similarity search results. Genome Res 5, 173-184.

Worley, K. C., Culpepper, P., Wiese, B. A. \& Smith, R. F. (1998). BEAUTY-X: enhanced BLAST searches for DNA queries. Bioinformatics 14, 890-891.

Zuker, M. (2003). Mfold web server for nucleic acid folding and hybridization prediction. Nucleic Acids Res 31, 3406-3415.

Edited by: C. W. Ronson 